\title{
PERANCANGAN APLIKASI PERAWATAN DAN PENITIPAN HEWAN PADA GARDEN 7 PETSHOP BERBASIS ANDROID (DESIGN OF ANIMAL CARE AND CARE AT GARDEN 7 PETSHOP BASED ON ANDROID)
}

\author{
Annisa Amelia ${ }^{1}$, Bertha Meyke Waty Hutajulu², Dewi \\ Anjani $^{3}$ \\ Program Studi Teknik Informatika, Fakultas Teknik dan Ilmu Komputer, \\ Universitas Indraprasta PGRI \\ anisaamelia2103@gmail.com ${ }^{1}$, bertha.hutadjoloe@gmail.com ${ }^{2}$, \\ dewiunindra@gmail.com
}

Received: July 30, 2021. Revised: August 08, 2021. Accepted: September 04, 2021. Issue Period: Vol.5, No.4 (2021) Page 741-759

\begin{abstract}
Abstrak: Jasa penitipan hewan merupakan salah satu solusi terbaik bagi sebagian besar masyarakat indonesia. Namun, dalam melakukan proses bisnisnya selama ini masih menggunakan pencatatan secara manual yang terkadang menyebabkan kerugian baik dalam hal materi maupun kepercayaan pelanggan. Tujuan penelitian ini untuk menanggulangi permasalahan tersebut, yaitu dengan merancang sistem pengelolaan perawatan dan penitipn hewan peliharaan secara terintegrasi dan terorganisir lebih baik dengan memanfaatkan teknologi informasi yang sudah berkembang pesat. Metodologi dalam penelitian ini menggunakan pendekatan kualitatif, dengan mengumpulkan data yang berhubungan dengan masalah-masalah yang hendak diteliti dan perancangan aplikasi yang digunakan adalah aplikasi android. Bedasarkan peneliti yang telah dilakukan, dihasilkan luaran tampilantampilan layar aplikasi seperti tampilan splashscreen, login, pelayanan, produk, pembayaran hingga laporan cetak faktur. Maka dari itu, berdasarkan aplikasi yang dikembangkan didapatkan hasil bahwa perancangan aplikasi perawatan dan penitipan hewan pada Garden 7 Petshop dapat dijadikan sebagai sarana untuk memudahkan transaksi pembelian dan penjualan, agar mudah untuk mengetahui jumlah stok barang, sebagai sarana untuk memudahkan pelayanan dan agar dihasilkan laporan-laporan yang lebih cepat dan akurat.
\end{abstract}

Kata kunci: Perancangan, Aplikasi, Perawatan dan Penitipan Hewan, Android.

Abstract: Animal care services are one of the best solutions for most Indonesian people. However, in carrying out its business processes so far, they still use manual recording which sometimes causes losses both in terms of material and customer trust. The purpose of this study is to overcome these problems, namely by designing an integrated and better organized pet care and care management system by utilizing information technology that has developed rapidly. The methodology in this study uses a qualitative approach, by collecting data related to the problems to be studied and the design of the application used is the android application. Based on the researchers that have been carried out, the results from the application screen display such as splashscreen displays, logins, services, products, payments to invoice print reports. Therefore, based on the application developed, the results obtained are that the design of animal care and care at Garden 7 Petshop can be used as a means to facilitate buying and selling transactions, so that it is easy to find out the number of goods, as a means to facilitate service and so that reports are generated. which is faster and more accurate.

Keywords: Animal Design, Applications, Care and Care, Android. 


\section{PENDAHULUAN}

Teknologi informasi telah menjadi istilah yang populer saat ini. Namun, pemilik usaha yang masih awam terhadap teknologi informasi yang mungkin masih belum mengetahui bagaimana kegunaan teknologi informasi dalam bisnis mereka.

Seiring berjalannya waktu terlebih perkembangan dunia usaha yang sudah menggunakan digitalisasi, usaha petshop atau layanan terhadap hewan peliharaan mulai di pandang sebagai jenis usaha yang menjanjikan. Akan tetapi, terdapat permasalahan yang timbul dari perkembangan yang sangat pesat ini seperti penjualan secara online pada petshop ini masih belum tersedia sehingga pengolahan data yang dilayani dalam bentuk komputerisasi berbasis aplikasi masih sangat kurang. Hal ini akan mengurangi peminat atau pasar yang sekarang sudah terbiasa menggunakan teknologi yang serba cepat dan instan. Oleh karena itu banyak toko-toko sejenis seperti ini mulai bermunculan dengan berbagai macam fasilitas yang berbeda-beda dalam memenuhi kebutuhan customer dalam hal ini adalah layanan aplikasi. Untuk memenangkan pemilihan toko Petshop (Garden 7) oleh Customer dari kompetitor-kompetitor, maka harus ada sebuah alternatif baru dalam memberikan layanan.

Agar mandapatkan hasil yang maksimal maka di perlukan alat bantu atau sarana yang memadai, misalnya aplikasi yang dapat mengelola data perawatan dan penitipan hewan berbasis android dengan baik, sehingga pengembagan sistem informasi yang dapat melakukan pencatatan dapat memberikan informasi keadaan atau status hewan yang dititipkan melalui aplikasi sebagai alternatif baru untuk meningkatkan kepercayaan pelanggan kepada toko Garden 7. Alat pengolahan data berupa komputer beserta alat pendukungnya, serta sumber daya manusia untuk pengoprasiannya.

\section{METODE DAN MATERI}

\subsection{Metode Penelitian}

Metode penelitian atau cara yang ditempuh untuk mencapai tujuan tertentu. Kemudian ada satu istilah lain yang erat kaitannya dengan dua istilah ini, yakni teknik yaitu cara yang spesifik dalam memecahkan masalah tertentu yang ditemukan dalam melaksanakan prosedur.

Metedologi penelitian adalah sekumpulan peraturan, kegiatan, dan prosedur yang digunakan oleh pelaku suatu disiplin ilmu. Metedologi juga merupakan analisis teroris mengenai suatu cara metode. Penelitian merupakan suatu penyelidikan yang sistematis untuk meningkatkan sejumlah pengetahuan, juga merupakan suatu usaha yang sistematis dan terorganisasi untuk menyelidiki masalah tertentu yang memerlukan jawaban. Metode penelitian pada dasarnya merupakan cara ilmiah untuk mendapatkan data dengan tujuan dan kegunaan tertentu [4]. Cara ilmiah berarti kegiatan penelitian itu didasarkan pada ciri-ciri keilmuan yaitu rasioanl, empiris, dan sistematis [1].

Metode penelitian yang akan dipakai oleh penulis adalah metode grounded (grounded research) yaitu suatu metode penelitian yang mendasarkan diri kepada fakta dan menggunakan Analisa perbandingan bertujuan untuk mengadakan generalisasi empiris, menetapkan konsep-konsep, membuktikan teori dan mengembangkan teori dimana pengumpulan data dan Analisa data berjalan pada waktu yang bersamaan. Metode yang digunakan dalam grounded research adalah reaksi terhadap metode penelitian yang asanya varivikasi teori. Dalam grounded research, data merupakan sumber teori, dan teori tersebut grounded karena teori tersebut bedasarkan data. Data yang diperoleh dapat dibandingkan melalui kategori-kategori.

\subsection{Metode Pengumpulan data}

Metode pengumpulan data adalah teknik atau cara yang dilakukan oleh peneliti untuk mengumpulkan data. Pengumpulan data dilakukan untuk memperoleh informasi yang dibutuhkan dalam rangka mencapai tujuan penelitian. Sementara itu instrumen pengumpulan data merupakan alat yang digunakan untuk mengumpulkan data.

Angket kepada karyawan Petshop di Bekasi yang bertujuan untuk mengetahui analisa kebutuhan yang dapat mengelola data perawatan dan penitipan hewan dengan baik, sehingga dapat mempercepat serta mengefisiensikan pekerjaan pengolahan data barang. Angket adalah daftar pertanyaan tertulis yang diberikan kepada subjek yang teliti untuk mengumpulkan informasi yang di butuhkan peneliti [3]. Angket merupakan 
salah satu alat pengumpul data dalam asesmen nontes, berupa serangkaian pertanyaan atau pernyataan yang diajukan pada responden (peserta didik, orang tua, atau masyarakat) [2]. Winkel [2] mendefinisikan angket sebagai suatu daftar atau kumpulan pertanyaan tertulis yang harus dijawab secara tertulis juga. Beberapa fungsi dari angket [2], yaitu sebagai berikut:

1. Mengumpulkan informasi sebagai bahan dasar dalam rangka penyusunan program.

2. Untuk menjamin validasi informasi yang diperoleh dengan metode lain.

3. Untuk mengambil sampling, sikap/ pendapat dari responden.

\section{PEMBAHASA DAN HASIL}

3.1 Definisi Masalah

Adapun masalah yang dihadapi oleh Garden 7 Petshop untuk menangani proses pelayanan dan penjualan, yaitu:

a. Tidak terdapat penyimpanan data berbasis database, sehingga proses pengolahan dan pencarian data pelayanan dan penjualan Garden 7 Petshop menjadi lama.

b. Dibutuhkan suatu aplikasi yang dapat mempermudah pengolahan data pada Petshop sehingga dapat membantu kinerja menjadi lebih optimal.

3.2 Penyelesaian Masalah

Adapun masalah yang dihadapi oleh Garden 7 Petshop untuk menangani proses pelayanan dan penjualan, yaitu: Proses penginputan penjualan yang dapat dilakukan melalui smartphone.

a. Aplikasi ini dapat mempercepat serta mengefisiensikan pekerjaan pengolahan data transaksi pada Garden 7 Petshop.

b. Dapat menyimpan data didalam database agar mudah dalam pencarian barang maupun laporan pelayanan dan penjualan.

\subsection{ALGORITMA PENYELESAIAN MASALAH DENGAN FLOWCHART DAN PSEUDOCODE} Aplikasi yang Digunakan oleh Penjual

Flowchart 


\section{Pseudocode}

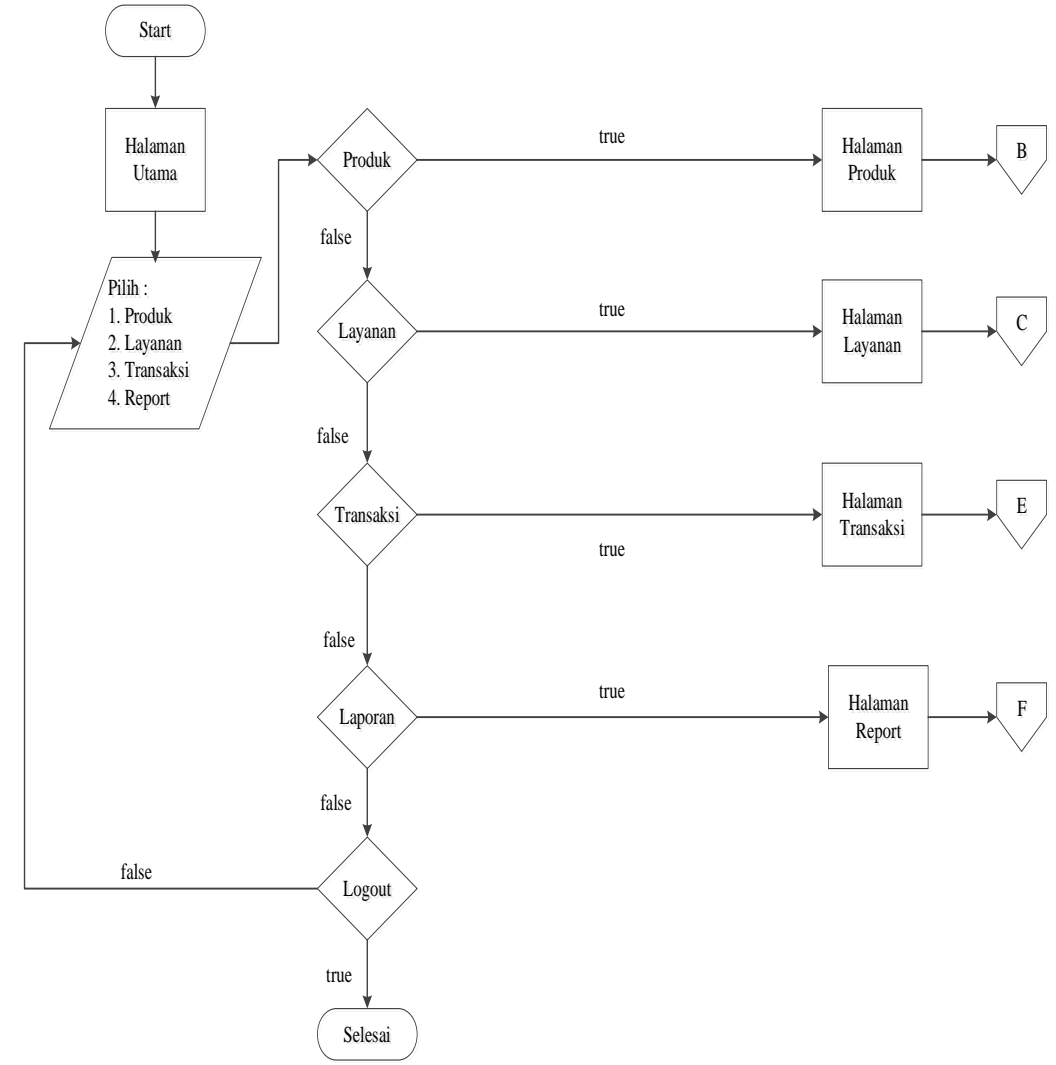

HalamanUtama.create()

Button_Produk.create()

Button_Pelayanan.create()

Button_Transaksi.create()

Button_Laporan.create()

If Button_Produk.click()

If Button_Produk.start()

If Button_Pelayanan.click()

If Button_Pelayanan.start()

If Button_Transaksi.click()

If button_Transaksi.start()

If Button_Laporan.click ()

If Button_Laporan.start()

Else Keluar.click()

Then app.close()

End if

Aplikasi yang Digunakan oleh Pembeli

Flowchart

Gambar 1. Flowchart Halaman Utama 


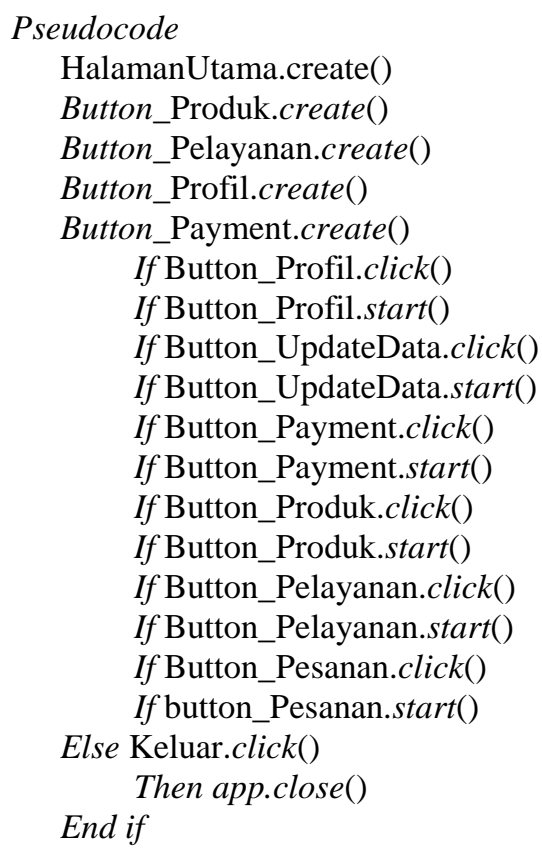

HalamanUtama.create()

Button_Produk.create()

Button_Pelayanan.create()

Button_Profil.create()

Button_Payment.create()

If Button_Profil.click ()

If Button_Profil.start()

If Button_UpdateData.click ()

If Button_UpdateData.start()

If Button_Payment.click()

If Button_Payment.start ()

If Button_Produk.click ()

If Button_Produk.start ()

If Button_Pelayanan.click()

If Button_Pelayanan.start()

If Button_Pesanan.click ()

If button_Pesanan.start ()

Else Keluar.click()

End if

$$
\text { Then app.close() }
$$

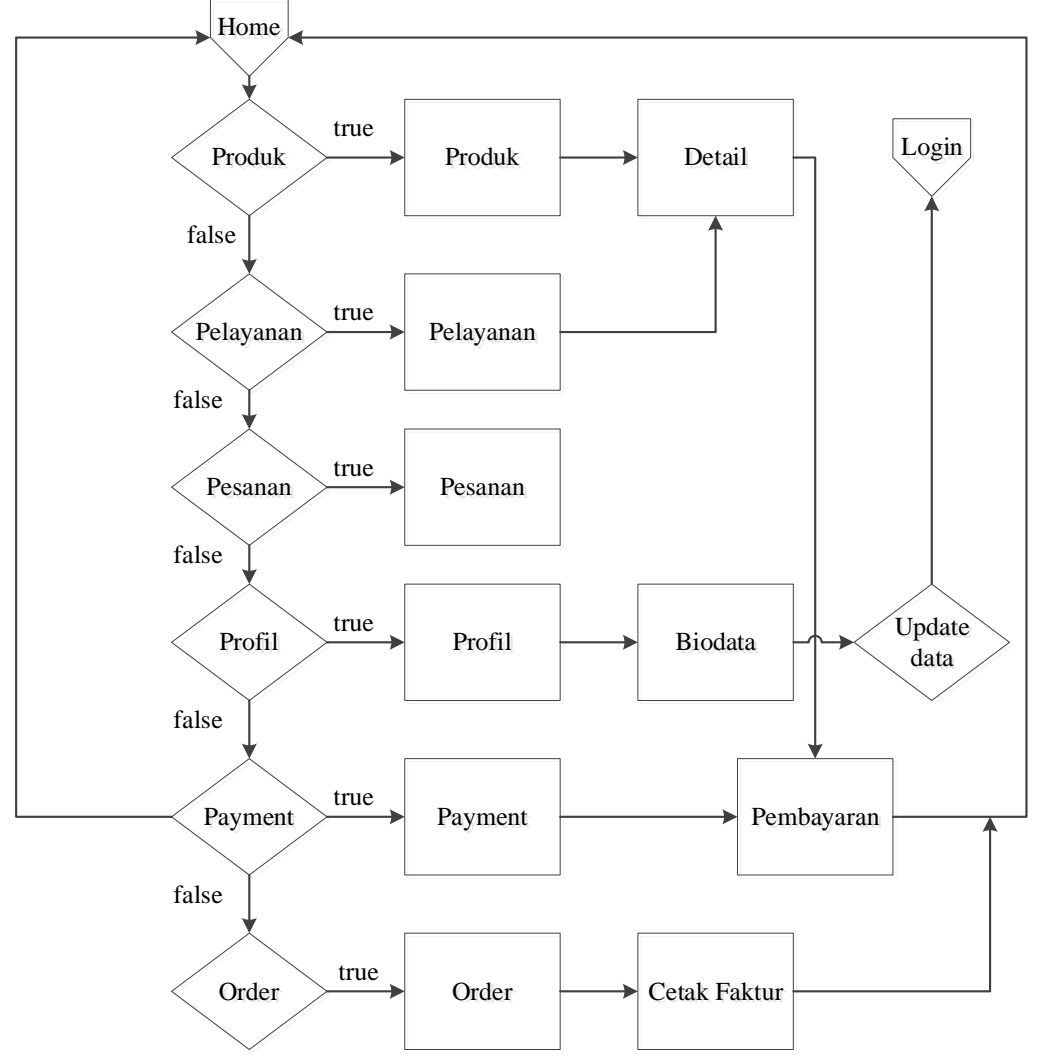

Gambar 2. Flowchart Halaman Utama

3.4 Tampilan Layar 
Journal of Information System, Applied, Management, Accounting and Research.

http://journal.stmikjayakarta.ac.id/index.php/jisamar, jisamar@stmikjayakarta.ac.id, jisamar2017@gmail.com

e-ISSN: 2598-8719 (Online), p-ISSN: 2598-8700 ( Printed), Vol. 5 No.4, November 2021

Berikut tahapan implementasi dan pengujian pada software program yang telah di buat dengan bahasa pemrograman jav dan php.

Aplikasi yang Digunakan oleh Penjual

Tampilan Halaman Utama

Halaman utama adalah tampilan program yang menampilkan menu program yang ingin dipilih.

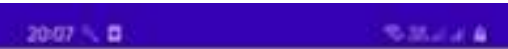

\section{Silakan Pilih Menu}

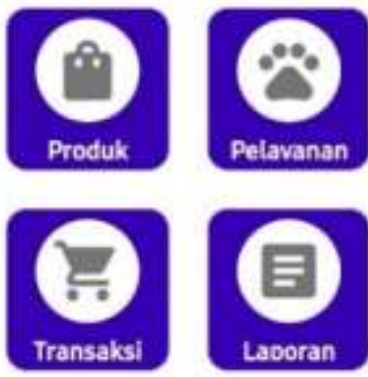

Gambar 3. Tampilan Halaman Utama

Tampilan Menu Produk

Menu produk adalah tampilan program yang akan menampilkan daftar produk penjualan dan menambahkan produk. 
Journal of Information System, Applied, Management, Accounting and Research. http://journal.stmikjayakarta.ac.id/index.php/jisamar , jisamar@stmikjayakarta.ac.id, jisamar2017@gmail.com e-ISSN: 2598-8719 (Online), p-ISSN: 2598-8700 ( Printed), Vol. 5 No.4, November 2021

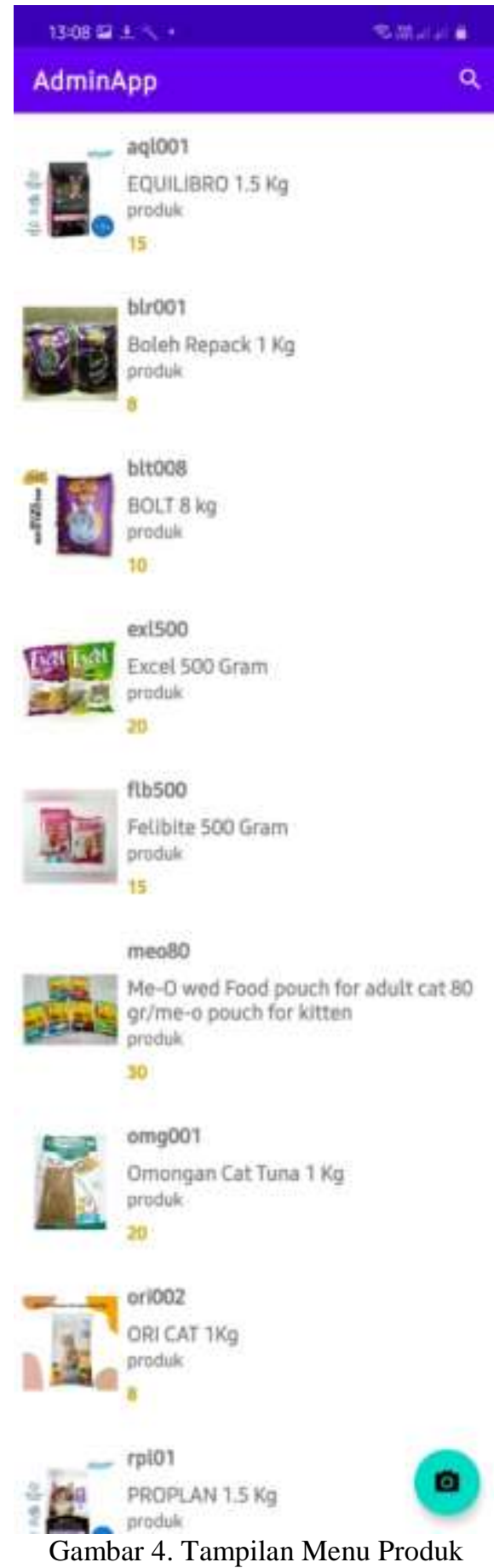

Tampilan Menu Pelayanan

Menu pelayanan adalah tampilan program yang akan menampilkan daftar pelayanan dan menambahkan pelayanan.

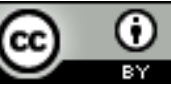


Journal of Information System, Applied, Management, Accounting and Research. http://journal.stmikjayakarta.ac.id/index.php/jisamar, jisamar@stmikjayakarta.ac.id, jisamar2017@gmail.com e-ISSN: 2598-8719 (Online), p-ISSN: 2598-8700 ( Printed), Vol. 5 No.4, November 2021

Tampilan Menu Transaksi

Gambar 5. Tampilan Menu Pelayanan

Menu transaksi adalah tampilan program yang akan menampilkan total pembelian.

Silakan Pilih Menu

\section{Produk}

Pelayanan

Tampilan Menu Laporan

Gambar 6. Tampilan Menu Transaksi

Menu laporan adalah tampilan program yang menampilkan laporan penjualan produk, laporan pelayanan dan laporan stok penjualan. 


\begin{tabular}{|c|c|c|c|c|}
\hline \multicolumn{3}{|c|}{ Laporan Penjualan Produk Bulan } & \multicolumn{2}{|l|}{ : Jul } \\
\hline No. & Tanggal & Nama & Produk \& Kuantitas & Total \\
\hline 1 & $\begin{array}{l}17-J u l \cdot 2021 \\
14: 15\end{array}$ & nur isnaini & $\begin{array}{l}\text { Excel } 500 \mathrm{Gram}-1, \mathrm{Me}-0 \text { wed Food pouch } \\
\text { for adult cat } 80 \mathrm{gr} / \mathrm{me} \text {-0 pouch for kitten }-2 \text {, }\end{array}$ & 22000 \\
\hline 2 & $\begin{array}{l}17-5 \text { ul-2021 } \\
14: 19\end{array}$ & Nandinda & Royal Canin 400 Gram-3, & 162000 \\
\hline 3 & $\begin{array}{l}17 \cdot \mathrm{Jul}-2021 \\
14: 33\end{array}$ & azhara & Omongan Cat Tuna $1 \mathrm{Kg}-1$, & 23000 \\
\hline 4 & $\begin{array}{l}\text { 17-Jul-2021 } \\
11=07\end{array}$ & muhammad kelvin & Whiskas-2, & 56000 \\
\hline 5 & $\begin{array}{l}17-J u l-2021 \\
13222\end{array}$ & muhammad kelvin & Whiskas-1, & 28000 \\
\hline 6 & $\begin{array}{l}\text { 17-Jul-2021 } \\
13: 42\end{array}$ & muhammad kelvin & EQUILIBRO $1.5 \mathrm{Kg}-1$, & 134000 \\
\hline 7 & $\begin{array}{l}\text { 17-Jul-2021 } \\
13: 53\end{array}$ & muhammad kelvin & PROPLAN $1.5 \mathrm{Kg}-1$, & 196000 \\
\hline 8 & $\begin{array}{l}\text { 17-Jul-2021 } \\
14.35\end{array}$ & muhammad kelvin & PROPLAN 1.5 Kg-1, & 196000 \\
\hline
\end{tabular}

Jakarta, 17 Juli 2021

Garden 7 Petshop

Ayis Suganda

Gambar 8. Laporan Produk

Laporan Pelayanan

Laporan pelayanan adalah tampilan program yang akan menampilkan daftar pelayanan. 
Journal of Information System, Applied, Management, Accounting and Research.

http://journal.stmikjayakarta.ac.id/index.php/jisamar , jisamar@stmikjayakarta.ac.id, jisamar2017@gmail.com

\section{GARENT}

Laporan Penjualan Produk Bulan ～： Jul

\begin{tabular}{|l|l|l|l|l|}
\hline No. & Tanggal & Nama & Layanan \& Frekuensi & Total \\
\hline 1 & $\begin{array}{l}17-J u l-2021 \\
14: 05\end{array}$ & nur isnaini & Grooming Dog-1, & 100000 \\
\hline 2 & $\begin{array}{l}17-J u l-2021 \\
14: 19\end{array}$ & Nandinda & Grooming Cat-1, & 55000 \\
\hline 3 & $\begin{array}{l}17-J u l-2021 \\
14: 23\end{array}$ & azhara & Pethotel-2, & 100000 \\
\hline 4 & $\begin{array}{l}17-J u l-2021 \\
14: 04\end{array}$ & muhammad kelvin & Pethotel-1, & 50000 \\
\hline
\end{tabular}

Jakarta, 17 Julis 2021

Garden 7 Petshop

Ayis Suganda

Laporan stok penjualan adalah tampilan program yang akan menampilkan daftar stok barang. 
Journal of Information System, Applied, Management, Accounting and Research. http://journal.stmikjayakarta.ac.id/index.php/jisamar, jisamar@stmikjayakarta.ac.id, jisamar2017@gmail.com e-ISSN: 2598-8719 (Online), p-ISSN: 2598-8700 ( Printed), Vol. 5 No.4, November 2021

\begin{tabular}{|c|c|c|c|}
\hline \multicolumn{4}{|c|}{ GARDEV? } \\
\hline No. & Kode & Nama & Stok \\
\hline 1 & aqico1 & EQUILIBFO $1.5 \mathrm{Kg}$ & 10 \\
\hline 2 & blrool & Boleh Repack $1 \mathrm{Kg}$ & 8 \\
\hline 3 & bitoos & BOLT $8 \mathrm{~kg}$ : & 10 \\
\hline 4 & ex 1500 & Excel 500 Gram & 17 \\
\hline 5 & $f l b 500$ & Felibite $500 \mathrm{Gram}$ & 15 \\
\hline 6 & meoso & $\begin{array}{l}\text { Me-O wed food pouch for aduit cat } 80 \mathrm{gtime-o} \mathrm{pouch} \mathrm{for} \\
\text { kitten }\end{array}$ & 130 \\
\hline 7 & omg001 & Omongan Cat Tuna $1 \mathrm{Kg}$ & 17 \\
\hline 8 & oriog: & ORI CAT $1 \mathrm{~KB}$ & 8 \\
\hline 9 & iplo1 & PROPLAN $1.5 \mathrm{Kg}$ & 18 \\
\hline 10 & ry/400 & Royal Canin 400 Gram & 4 \\
\hline 11 . & wks 480 & Whiskas 480 Gram & 1 \\
\hline
\end{tabular}

Jakarta, 17 Juli 2021

Garden 7 Petshop

Ayis Suganda

Gambar 10. Tampilan Laporan Stok Penjualan 
Journal of Information System, Applied, Management, Accounting and Research.

http://journal.stmikjayakarta.ac.id/index.php/jisamar,

jisamar@stmikjayakarta.ac.id, jisamar2017@gmail.com

e-ISSN: 2598-8719 (Online), p-ISSN: 2598-8700 ( Printed), Vol. 5 No.4, November 2021

Aplikasi yang Digunakan oleh Pembeli

Tampilan Splashscreen

Splashscreen adalah tampilana awal pada program ini yang menampilkan logo dari program petshop sebelum masuk ke tampilan selanjutnya .
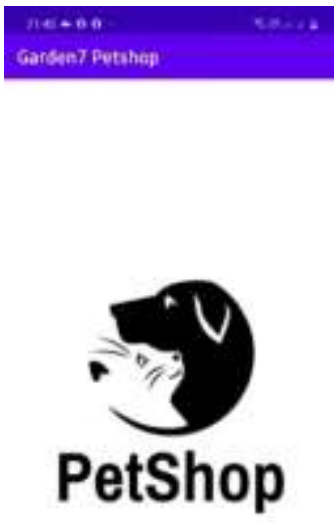

Gambar 11. Tampilan Splashscreen

Tampilan Menu Login

Login adalah tampilan program yang akan menampilkan sebuah formular berisikan Username dan Password yang harus di isi bila ingin masuk ke halaman utama.
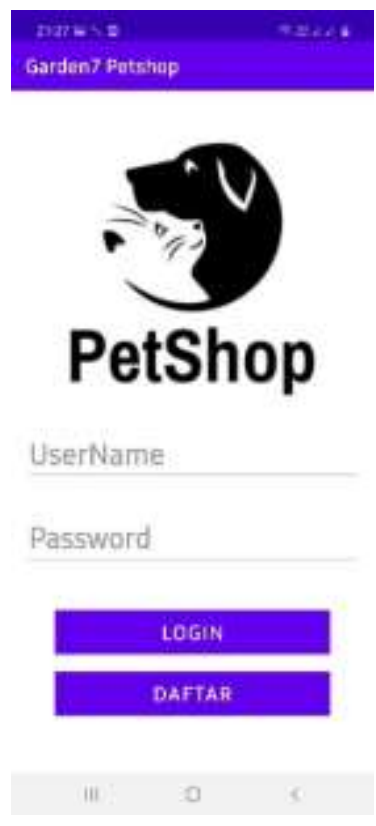

Gambar 12. Tampilan Login 
Journal of Information System, Applied, Management, Accounting and Research.

http://journal.stmikjayakarta.ac.id/index.php/jisamar, jisamar@stmikjayakarta.ac.id, jisamar2017@gmail.com e-ISSN: 2598-8719 (Online), p-ISSN: 2598-8700 ( Printed), Vol. 5 No.4, November 2021

Tampilan Menu Pelayanan

Menu pelayanan adalah tampilan program yang akan menampilkan daftar pelayanan.
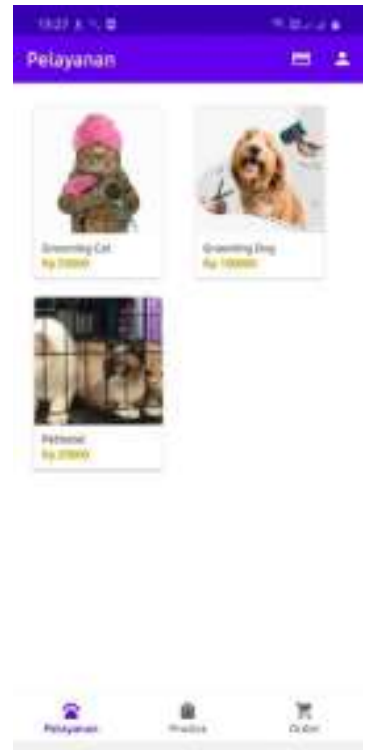

Gambar 13. Tampilan Pelayanan

Tampilan Menu Produk

Menu produk adalah tampilan program yang akan menampilkan daftar produk.

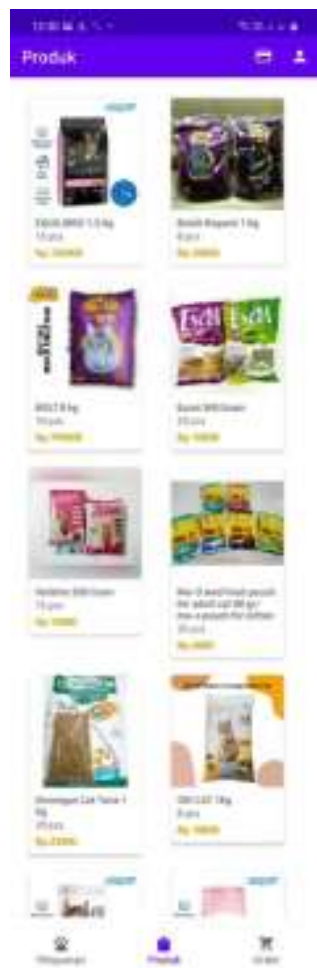

Gambar 14. Tampilan Produk 
Journal of Information System, Applied, Management, Accounting and Research.

http://journal.stmikjayakarta.ac.id/index.php/jisamar, jisamar@stmikjayakarta.ac.id, jisamar2017@gmail.com

e-ISSN: 2598-8719 (Online), p-ISSN: 2598-8700 ( Printed), Vol. 5 No.4, November 2021

Tampilan Detail Produk

Detail produk adalah salah satu tampilan yang menampilkan deskripsi produk secara lengkap.

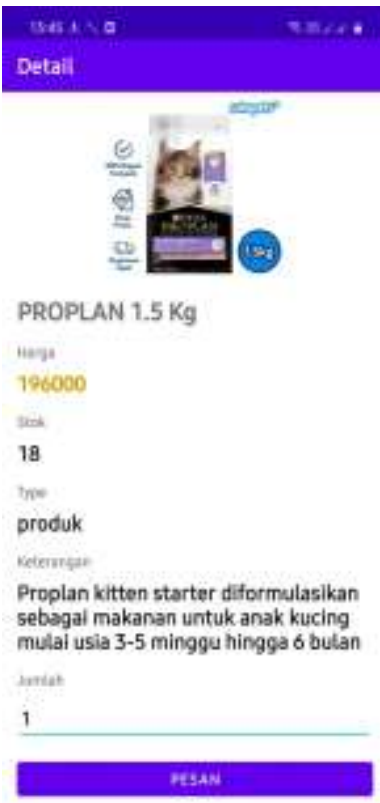

Gambar 15. Tampilan Detail Produk

Tampilan Payment

Detail pembayaran adalah tampilan yang menampilkan tentang total harga pesanan secara keseluruhan.

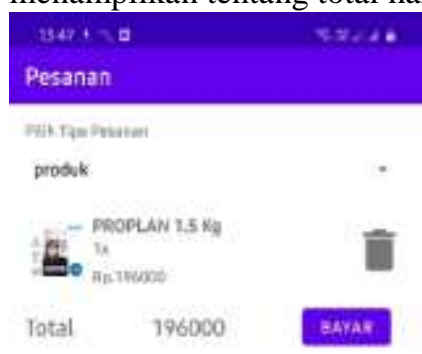

Gambar 16. Tampilan Payment 
Journal of Information System, Applied, Management, Accounting and Research.

http://journal.stmikjayakarta.ac.id/index.php/jisamar, jisamar@stmikjayakarta.ac.id, jisamar2017@gmail.com

e-ISSN: 2598-8719 (Online), p-ISSN: 2598-8700 ( Printed), Vol. 5 No.4, November 2021

Tampilan Konfirmasi Pembayaran

Konfirmasi Pembayaran adalah salah satu tampilan yang menampilkan tentang rincian pembayaran yang harus di konfirmasi pada penjual.

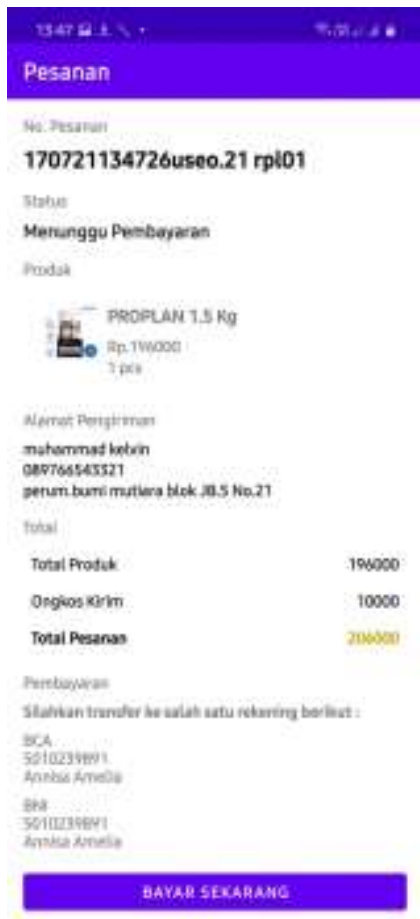

Gambar 17. Tampilan Konfirmasi Pembayaran

Tampilan Bukti Pembayaran

Bukti pembayaran adalah dokumentasi yang menjadi alat untuk merekan seluruh transaksi yang terjadi.
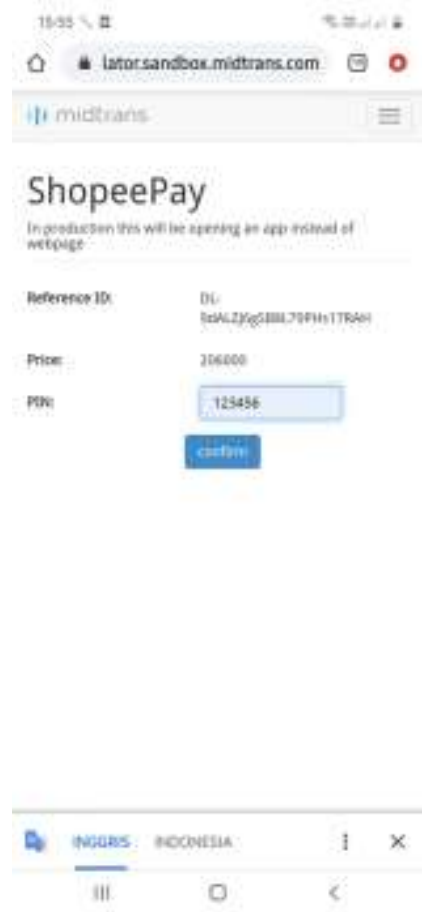

Gambar 18. Tampilan Bukti Trnasfer

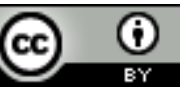


Journal of Information System, Applied, Management, Accounting and Research. http://journal.stmikjayakarta.ac.id/index.php/jisamar, jisamar@stmikjayakarta.ac.id, jisamar2017@gmail.com e-ISSN: 2598-8719 (Online), p-ISSN: 2598-8700 ( Printed), Vol. 5 No.4, November 2021

Tampilan Order

Order adalah tampilan tentang proses kemajuan pesanan yang telah di beli.

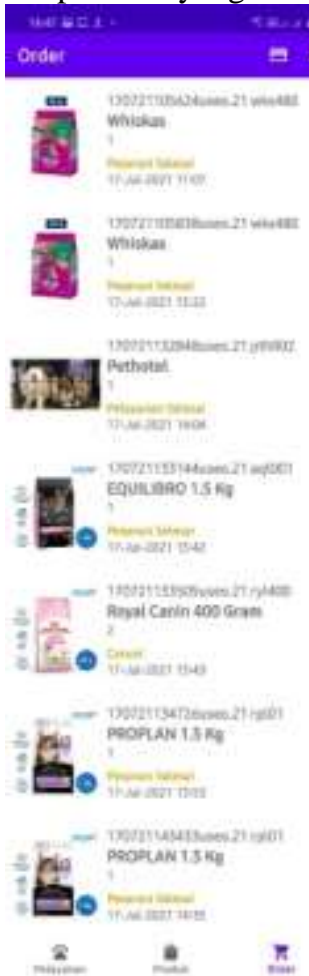

Laporan Cetak Faktur

Gambar 19. Tampilan Order

Order adalah tampilan tentang proses kemajuan pesanan yang telah di beli.

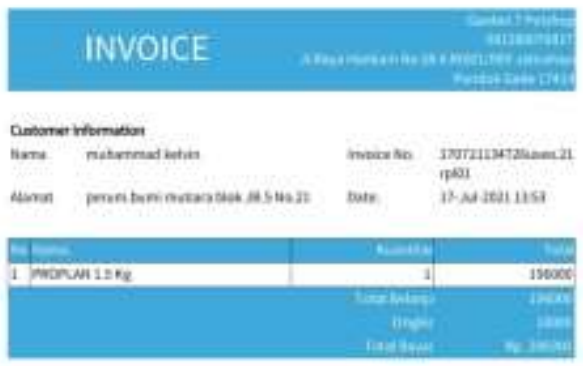

Gambar 20. Laporan Cetak Faktur 


\section{KESIMPULAN}

Bedasarkan uraian dan analisa, maka pada laporan tugas akhir ini yang berjudul "Perancangan Aplikasi "Perancangan Aplikasi Perawatan dan Penitipan Hewan pada Garden 7 Petshop Berbasis Android "dapat diambil kesimpulan sebagai berikut:

1. Sebagai sarana untuk memudahkan transaksi pembelian dan penjualan, agar meminimalisir terjadinya kesalahan.

2. Agar mudah untuk mengetahui jumlah stok barang, sehingga dapat menghindari terjadinya stok minus.

3. Sebagai sarana untuk memudahkan pelayanan seperti, penitipan dan perawatan hewan.

4. Agar dihasilkan laporan-laporan yang lebih cepat dan akurat.

\section{REFERENASI}

[1] Darmadi, Hamid. 2013. Metode Penelitian Pendidikan dan Sosial. Bandung: Alfabeta.

[2] Komalasari, dkk. 2011. Asesmen Teknik Notes dalam Perspektif BK Komprehensif. Jakarta: PT.Indeks.

[3] Kusumah, Wijaya. 2011 Penelitian Tindakan Kelas. Jakarta: PT.Indeks.

[4] Sugiyono. 2013. Metode Penelitian Pendidikan Pendekatan Kuantitatif, Kualitatif dan R\&D. Bandung: Alfabeta.

[5] Adi Mardian, Thomas Budiman, Rachmawaty Haroen; Verdi Yasin (2021), Perancangan Aplikasi Pemantauan Kinerja Karyawan Berbasis Android di PT. Salestrade Corp. Indonesia, "Jurnal Manajemen Informatika Jayakarta", E-ISSN : 2797-0930 (Online), P-ISSN : 2746-5985 (Print), Volume 1, Nomor 3,Juli 2021, halaman 169-185, DOI: 10.52362/jmijayakarta.v1i3.481, URL Publikasi: http://journal.stmikjayakarta.ac.id/index.php/JMIJayakarta/article/view/481

[6] Nandang Mulyana, Agus Sulistyanto, Verdi Yasin (2021), Perancangan sistem informasi pengelolaan aset it berbasis web pada pt mandiri axa general insurance, "Jurnal Manajemen Informatika Jayakarta", E-ISSN : 2797-0930 (Online), P-ISSN : 2746-5985 (Print), Volume 1, Nomor 3, Juli 2021, halaman 243-257, DOI: 10.52362/jmijayakarta.v1i3.498, URL Publikasi: http://journal.stmikjayakarta.ac.id/index.php/JMIJayakarta/article/view/498

[7] Maulia Usnaini, Verdi Yasin, Anton Zulkarnain Sianipar (2021), Perancangan sistem informasi inventarisasi aset berbasis web menggunakan metode waterfall, "Jurnal Manajemen Informatika Jayakarta", E-ISSN : $2797-$ 0930 (Online), P-ISSN : 2746-5985 (Print) Volume 1, Nomor 1,Februari 2021, halaman 36-55, DOI: 10.52362/jmijayakarta.v1i1.415, URL Publikasi: http://journal.stmikjayakarta.ac.id/index.php/JMIJayakarta/article/view/415

[8] Putri Setiani, Ifan Junaedi, Anton Zulkarnain Sianipar, Verdi Yasin (2021), Perancangan sistem informasi pelayanan penduduk berbasis website di rw 010 Kelurahan Keagungan Kecamatan Tamansari - Jakarta Barat. "Jurnal Manajemen Informatika Jayakarta", E-ISSN : 2797-0930 (Online), P-ISSN : 2746-5985 (Print) Volume 1, Nomor 1,Februari 2021, halaman 20-35, DOI: 10.52362/jmijayakarta.v1i1.414, URL Publikasi: http://journal.stmikjayakarta.ac.id/index.php/JMIJayakarta/article/view/414

[9] Benni Triyono, Sri Purwanti, Verdi Yasin (2017) “Rekayasa Perangkat Lunak Sistem Informasi Pengiriman Dan Penerimaan Surat Atau Paket Berbasis Web", Journal of Information System, Applied, Management, Accounting and Research, e-ISSN: 2598-8719. p-ISSN: 2598-8700.Vol.1 No.1 (30 Desember 2017) p46-53 http://journal.stmikjayakarta.ac.id/index.php/jisamar/article/view/12

[10] Verdi Yasin, Muhammad Zarlis, Mahyuddin K.M. Nasution (2018) “Filsafat Logika Dan Ontologi Ilmu Komputer", Journal of Information System, Applied, Management, Accounting and Research, e-ISSN: 2598-8719. p-ISSN: 2598-8700.Vol.2 No.2 (19 Juni 2018) p68-75 http://journal.stmikjayakarta.ac.id/index.php/jisamar/article/view/39

[11] Julinda Maya Paramudita, Verdi Yasin (2019) "Perancangan Aplikasi Sistem Penyewaan Alat Berat ", Journal of Information System, Applied, Management, Accounting and Research, e-ISSN: 2598-8719. p-ISSN: 25988700.Vol.3 No.1 (20 Februari 2019) p23-29 http://journal.stmikjayakarta.ac.id/index.php/jisamar/article/view/73

[12] Muryan Awaludin, Verdi Yasin (2020) "Application Of Oriented Fast And Rotated Brief (Orb) And Bruteforce Hamming In Library Opencv For Classification Of Plants", Journal of Information System, Applied, 
Journal of Information System, Applied, Management, Accounting and Research. http://journal.stmikjayakarta.ac.id/index.php/jisamar, jisamar@stmikjayakarta.ac.id, jisamar2017@gmail.com e-ISSN: 2598-8719 (Online), p-ISSN: 2598-8700 ( Printed), Vol. 5 No.4, November 2021

Management, Accounting and Research, e-ISSN: 2598-8719. p-ISSN: 2598-8700.Vol.4 No.3 (14 Agustus 2020) p51-59 http://journal.stmikjayakarta.ac.id/index.php/jisamar/article/view/247

[13] Ifan Junaedi, Dimas Abdillah, Verdi Yasin (2020) “Analisis Perancangan Dan Pembangunan Aplikasi Business Intelligence Penerimaan Negara Bukan Pajak Kementerian Keuangan RI", Journal of Information System, Applied, Management, Accounting and Research, e-ISSN: 2598-8719. p-ISSN: 2598-8700.Vol.4 No.3 (14 Agustus 2020) p88-101 http://journal.stmikjayakarta.ac.id/index.php/jisamar/article/view/249

[14] Verdi Yasin (2012) 'Rekayasa Perangkat Lunak Berorientasi Objek”, Penerbit: Mitra Wacana Media, JakartaIndonesia.

[15] Anis Rohmadi, Verdi Yasin (2020) “Desain Dan Penerapan Website Tata Kelola Percetakan Pada CV Apicdesign Kreasindo Jakarta Dengan Metode Prototyping", Journal of Information System, Informatics and Computing. E-ISSN: 2597-3673 (Online), P-ISSN: 2579-5201 (Print) Vol. 4 No.1, June 22, 2020. Pp.70-85 http://journal.stmikjayakarta.ac.id/index.php/jisicom/article/view/210

[16] Septian Cahyadi, Verdi Yasin, Mohammad Narji, Anton Zulkarnain Sianipar (2020) "Perancangan Sistem Informasi Pengiriman Dan Penerimaan Soal Ujian Berbasis Web ( Studi Kasus: Fakultas Komputer Universitas Bung Karno)", Journal of Information System, Informatics and Computing._E-ISSN: 2597-3673 (Online), P-ISSN: 2579-5201 (Print) Vol. 4 No.1, June 22, 2020. Pp.1-16 http://journal.stmikjayakarta.ac.id/index.php/jisicom/article/view/199

[17] Ifan Junaedi, Ndaru Nuswantari, Verdi Yasin (2019) "Perancangan Dan Implementasi Algoritma C4.5 Untuk Data Mining Analisis Tingkat Risiko Kematian Neonatum Pada Bayi", Journal of Information System, Informatics and Computing. E-ISSN: 2597-3673 (Online), P-ISSN: 2579-5201 (Print) Vol. 3 No.1, February 13, 2019. Pp.29-44. http://journal.stmikjayakarta.ac.id/index.php/jisicom/article/view/203

[18] Verdi Yasin, Anindra Ramdhan Nugraha, Muhammad Zarlis, Ifan Junaedi (2018) "Smart System Of Fast Internet Access Development Using Backbone Network Method", Journal of Information System, Informatics and Computing._E-ISSN: 2597-3673 (Online), P-ISSN: 2579-5201 (Print) Vol. 2 No. 2, December 31, 2018. Pp.26-34. http://journal.stmikjayakarta.ac.id/index.php/jisicom/article/view/198

[19] Ito Riris Immasari, Verdi Yasin (2019) “Penggunaan Metode Analytic Hierarchy Process Untuk Menganalisis Faktor-Faktor Yang Mempengaruhi Pemilihan Calon Legislatif Di Dprd li Kota Tangerang”, Journal of Information System, Informatics and Computing. E-ISSN: 2597-3673 (Online), P-ISSN: 2579-5201 (Print) Vol. 3 No. 2, December 10, 2019. Pp.53-58.

http://journal.stmikjayakarta.ac.id/index.php/jisicom/article/view/139

[20] Verdi Yasin, Muhammad Zarlis, Tulus, Erna Budhiarti Nababan, Poltak Sihombing (2019) “Rancangan Miniatur Otomatisasi Bel Listrik Pada Gerbang Pintu Menggunakan Microkontroler Atmega8535", Journal of Information System, Informatics and Computing. E-ISSN: 2597-3673 (Online), P-ISSN: 2579-5201 (Print) Vol. 3 No. 1, February 13, 2019. Pp.13-20 http://journal.stmikjayakarta.ac.id/index.php/jisicom/article/view/68

[21] Anggeri S. Nurjaman, Verdi Yasin (2020) “Konsep Desain Aplikasi Sistem Manajemen Kepegawaian Berbasis Web Pada PT. Bintang Komunikasi Utama ", Journal of Information System, Informatics and Computing._EISSN: 2597-3673 (Online), P-ISSN: 2579-5201 (Print) Vol. 4 No. 2, December 28, 2020. Pp.143-174 http://journal.stmikjayakarta.ac.id/index.php/jisicom/article/view/363

[22] Verdi Yasin, Azhar Ahmad Riza, Rumadi Hartawan (2017) “Pengembangan Aplikasi Pemulihan Layanan Bencana Sistem Informasi Peneriman Negara Bukan Pajak Online Di Lingkungan Kementerian Keuangan Republik Indonesia", Journal of Information System, Informatics and Computing. E-ISSN: 2597-3673 (Online), P-ISSN: 2579-5201 (Print) Vol. 1 No. 1, September 20, 2017. Pp.33-56. http://journal.stmikjayakarta.ac.id/index.php/jisicom/article/view/4

[23] Verdi Yasin (2021) "Penerapan sistem kegiatan belajar dan mengajar dalam instrumen sertifikasi dosen profesional menggunakan metode SMART”, Tridharmadimas: Jurnal Pengabdian Kepada Masyarakat, DOI: 10.52362/tridharmadimas.v1i1.501, E-ISSN : 2798-8295 (Online), P-ISSN : 2798-8554 (Print), Vol.1 No.1, July 24, 2021 Page 37-55.

http://journal.stmikjayakarta.ac.id/index.php/tridharmadimas/article/view/501 